\title{
Intrarenal Reflux Diagnosed by Contrast-Enhanced Voiding Urosonography - a Case Report
}

\author{
Iva Palčić1, Andrea Cvitković Roić1, ${ }^{1,}$, Goran Roić ${ }^{2}$ \\ ${ }^{1}$ Clinic for pediatric disease Helena, Zagreb, Croatia, ${ }^{2}$ Children's Hospital Zagreb, Zagreb, Croatia, ${ }^{3}$ Josip Juraj Strossmayer \\ University of Osijek, Faculty of Medicine
}

Correspondence: iva.palcic@yahoo.com; Tel.: + 38512310 067; Fax.: + 3851231019

Received: December 9, 2020; Accepted: January 28, 2021

\begin{abstract}
Objective - Intrarenal reflux (IRR) is the main cause of renal injury in children with vesicoureteral reflux (VUR), and has an important role in the pathogenesis of scarring and reflux nephropaty (RN). Using voiding cystourethrography (VCUG) IRR is usually detected in high grades of VUR. Our case demonstrates the possibility of visualizing IRR in a child with low-grade VUR using contrast-enhanced voiding urosonography (ceVUS). Case Report - We report the case of a four-month-old girl with Klebsiella pneumoniae febrile urinary tract infection (UTI) who was diagnosed by ceVUS with VUR grade II on the right kidney, with IRR strongest in the lower pole. A 99m Tc 2.3-dimercaptosuccinic acid (DMSA) renal scan, which was performed 8 months after the UTI revealed a small scar on the lower pole of the right kidney, where IRR was found by ceVUS. Conclusion - Our case report showed that not only the grade of reflux but also the presence of IRR is important to predict the severity of the clinical picture and the development of possible scarring. It is important to find IRR because it may be connect with renal scars. VUR with IRR should be managed actively to decrease the chances of renal scarring or the development of new scars.
\end{abstract}

Key Words: Vesicoureteral Reflux • Intrarenal Reflux • Children • Contrast-Enhanced Voiding Urosonography • ceVUS.

\section{Introduction}

Intrarenal reflux (IRR) is a condition in which the urine refluxes into collecting systems in the nephron, and it can result in renal scarring (1). It was first described by Brodeur et al. in 1965 (2). The occurrence of IRR is closely related to the morphological features of the renal papillae. Papillae with a convex shape have an oblique duct end which produces a valvular effect and guards against backflow of the urine into the medullary collecting ducts. Papillae with a concave shape have ducts with right angle ends. These ends of the ducts are still open when intrapelvic pressure increases, which results in IRR (3). Concave papillae are mostly distributed on the poles of the kidneys where IRR is often found, as well as scarring (4). In the past voiding cystourethrography (VCUG) was the only practical diagnostic imaging modality available for IRR detection (5). Darge et al. reported that contrastenhanced harmonic ultrasonography (ceVUS) can also make the diagnosis of IRR even more precisely than VCUG, and at the same time prevents exposure to radiation (6).

Here we report the case of a girl with VUR grade II and IRR, confirmed by ceVUS.

\section{Case Report}

A 4-month-old girl presented with febrile Klebsiella pneumoniae UTI. As part of the routine work-up, ultrasound (US) of the kidneys and bladder was per- 
formed. The left kidney was normal, but the right kidney was swollen with hyperechogenic parenchyma. Its renal pelvic wall was thickened, but without dilatation. The bladder wall was normal and no dilated prevesical ureters were detected. After 10 days of antibiotic therapy she was put on antibiotic prophylaxis and 2 weeks later ceVUS was performed. The first precontrast scan of the kidneys and bladder was performed on a LOGIQ 8 machine (GE Healthcare, Milwaukee, WI), equipped with dedicated software for contrast-enhanced studies with harmonic imaging modality. The parenchyma of the

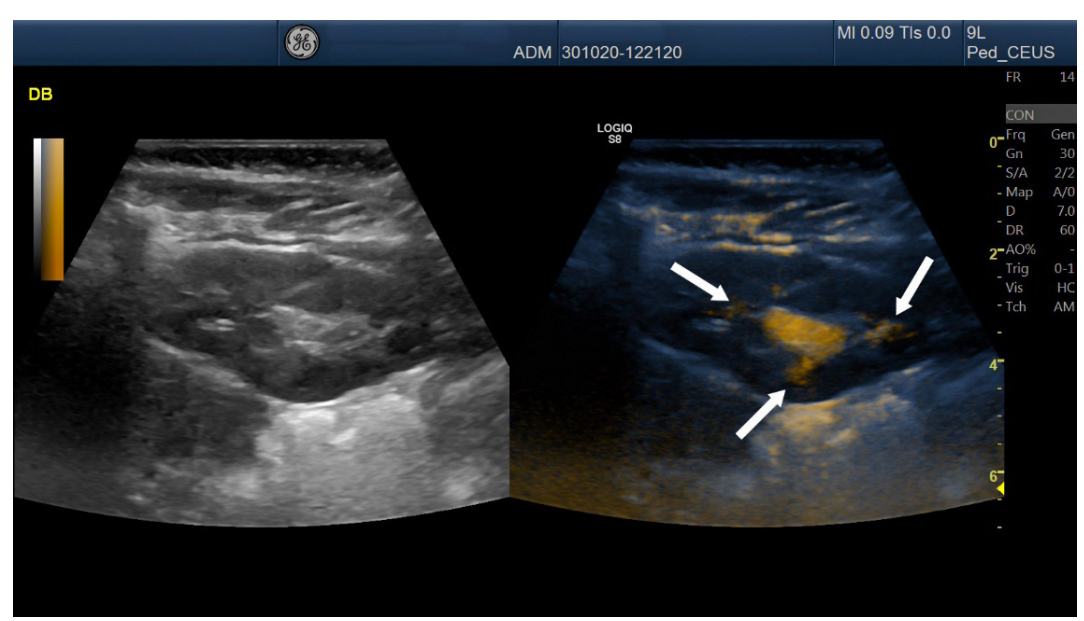

Fig. 1. Contrast-enhanced voiding urosonography (ceVUS): the appearance of contrast microbubbles outside the contours of the pelvicalyceal system confirms intrarenal reflux (IRR).

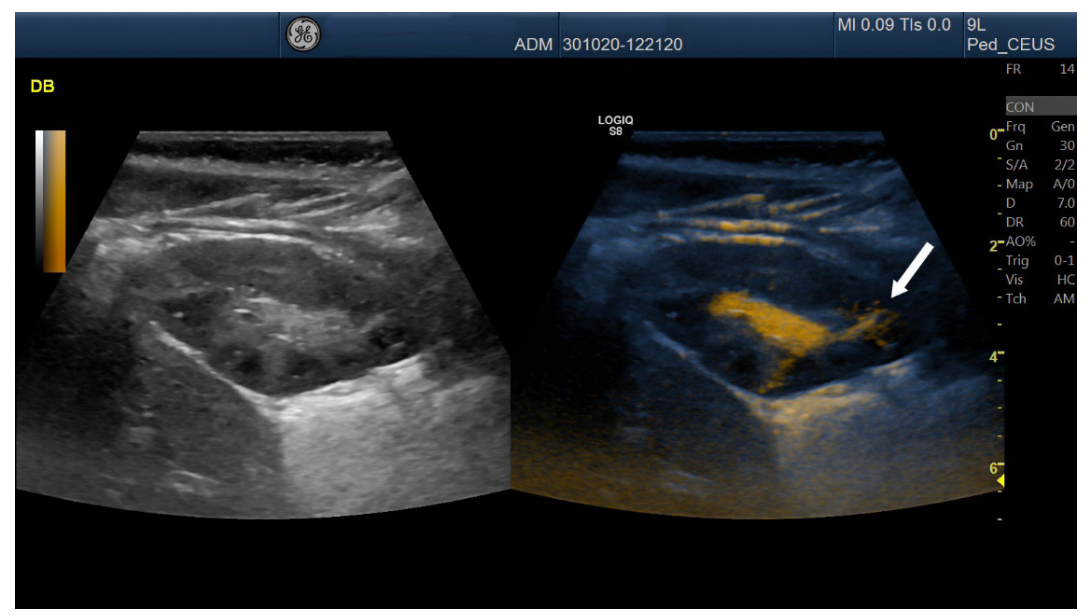

Fig. 2. Contrast-enhanced voiding urosonography (ceVUS): contrast microbubbles outside the contours of the pelvicalyceal system confirms intrarenal reflux (IRR) strongest in the lower pole of the right kidney. right kidney was no longer swollen, and its corticomedullary differentiation was normal, as were the ureters and bladder. Standard US of the urinary tract in supine and prone positions was followed by transurethral catheterisation, and administration of saline and a freshly prepared suspension of the US contrast medium (SonoVueR, Bracco). The bladder was progressively and homogeneously filled to its expected capacity. Bladder capacity (in milliliters) was calculated using the formula for children younger than 1 year (weight in kilograms $\times 7$ ). Continuous and alternate examination of the kidneys and bladder was performed during bladder filling and voiding.

In the middle of the filling phase, the microbubbles refluxed into the right ureter and entered into the renal pelvis without dilatation, but with the appearance of contrast microbubbles outside the contours of the pelvicalyceal system (Fig. 1). This was strongest in the lower pole of the right kidney (Fig. 2).

The entry of contrast microbubbles into the kidney parenchyma is a diagnostic sign of IRR (6), and the reflux of microbubbles into the right ureter and renal pelvis without dilatation, according to the five grade system of VUR using ceVUS developed by Darge and Troeger, represent VUR grade II (7). After 8 months on prophylaxis without UTI a 99m Tc 2,3-dimercaptosuccinic acid (DMSA) renal scan was performed. DMSA showed a small scar on the lower pole of the right kidney where the IRR had been found by ceVUS (Fig. 3). 


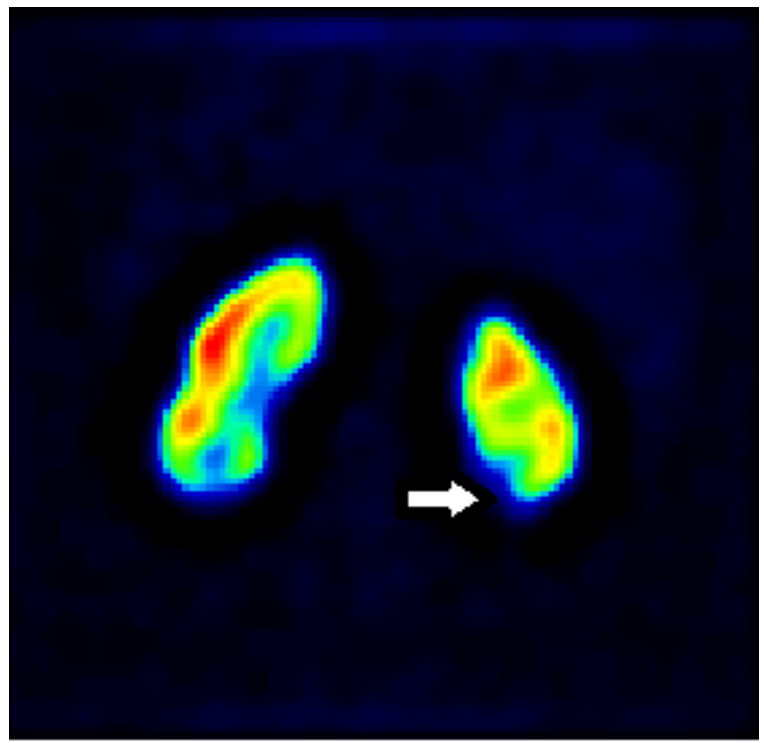

Fig. 3. $99 m$ Tc 2,3-dimercaptosuccinic acid (DMSA) renal scan showed a small scar on the lower pole of the right kidney.

\section{Discussion}

Vesicoureteral reflux (VUR) is one of the most common urinary tract anomalies in children and may be associated with reflux nephropathy $(\mathrm{RN})$ $(1,8)$. Intrarenal reflux (IRR) is a risk factor for $\mathrm{RN}$ and has a crucial role in the pathogenesis of scarred kidneys, as pointed out by Hodson and Ransley (8-10). The mechanisms of renal damage in IRR are the entry of bacteria into the renal tubular system directly and/or reduced renal blood flow due to an increase in intratubular pressure (11). The lack of published reports on IRR over the last 2 decades is perhaps because the management of VUR is primarily based on reflux grade. However, IRR has been identified as important in understanding the pathophysiology of reflux nephropathy (12). It was noticed that children with VUR accompanied by IRR are generally considered to have a more severe clinical picture, and more often develop scars (12), as happened to our patient. Many studies have confirmed that the distribution of renal scarring is almost identical to that of renal impairment $(4,12,13,14)$. Kim and al. in their retrospective study of 50 patients showed that cortical defects seen on Tc 99m DMSA correlated well with sites of IRR, and these sites tended to progress to renal scarring (15). Some authors even suggest that surgical interventions for VUR should be considered sooner in children with IRR than in those without IRR $(14,15)$. Our patient developed a small scar on the lower pole of the right kidney where the IRR was visualized most strongly, which confirms the importance of discovering IRR.

Studies using VCUG to detect IRR showed an incidence of $<1 \%$ to $10 \%(5,14,15)$. This is expected due to the various techniques used in VCUG, and because IRR is not a stable entity. When using VCUG, it may be missed due to inadequate bladder filling, the dilution of the radiographic contrast in the already dilated collecting system, obscuration by an overlying bowel shadow, low image quality, or too narrow collimation of the X-ray field, focusing only on the bladder and urethra during micturition (12). VCUG with pulsed fluoroscopy allows detection of IRR in up to $11 \%$ of patients with VUR $(5,12)$. Using ceVUS diagnosis of IRR can also be made even more precise than by using VCUG and, what is important in children, without using radiation $(6,13)$. In our case report we used ceVUS to show IRR. Schneider et al. showed that by using VCUG, IRR is usually detected in children with a higher grade of VUR, and often in the voiding phase (12). Our patient showed that by using ceVUS we can also detect IRR in children with a low grade of VUR.

\section{Conclusion}

It is important to find IRR because it may be connected with renal scars. In children, IRR usually accompanies high-grade VUR. Our case report shows that using ceVUS we can also see IRR in a patient with low-grade VUR. The case also shows that not only the grade of reflux but also the presence of IRR is important in predicting the severity of the clinical picture and the possible development of scarring. VUR with IRR should be actively managed to decrease the chances of renal scarring or the development of new scars. 


\section{References}

1. Bailey RR. The relationship of vesico-ureteric reflux to urinary tract infection and chronic pyelonephritis-reflux nephropathy. Clin Nephrol. 1973;1:132-41.

2. Brodeur AE, Goyer RA, Melick W. A potential hazard of barium cystography. Radiology. 1965;85:1080-4.

3. Hodson CJ, Twohill SA. The time factor in the development of sterile renal scarring following high-pressure vesicoureteral reflux. Contrib Nephrol. 1984;39:358-69.

4. Hannerz L, Wikstad I, Johansson L, Broberger O, Aperia A. Distribution of renal scars and intrarenal reflux in children with a past history of urinary tract infection. Acta Radiol. 1987;28:443-6.

5. Cremin BJ. Observations on vesico-ureteric reflux and intrarenal reflux: a review and survey of material. Clin Radiol. 1979;30:607-21.

6. Darge K, Trusen A, Gordjani N, Riedmiller H. Intrarenal reflux: diagnosis with contrast-enhanced harmonic US. Pediatr Radiol. 2003;33:729-31.

7. Darge K, Troeger J. Vesicoureteral reflux grading in contrast-enhanced voiding urosonography. Eur J Radiol. 2002;43:122-8.
8. Hodson CJ. Neuhauser lecture. Reflux nephropathy: a personal historical review. AJR. 1981;137:451-62.

9. Hodson CJ, Edwards D. Chronic pyelonephritis and vesico-ureteric reflux. Clin Radiol. 1960;11:219-31.

10. Ransley PG. Opacification of the renal parenchyma in obstruction and reflux. Pediatr Radiol. 1976;4:226-32.

11. Hodson CJ. The effects of disturbance of flow of the kidney. J Infect Dis. 1969;120:54-5.

12. Schneider KO, Lindemeyer K, Kammer B. Intrarenal reflux, an overlooked entity-retrospective analysis of 1,166 voiding cystourethrographies in children. Pediatr Radiol. 2019;49(5):617-25.

13. Colleran GC, Barnewolt CE, Chow JS, Paltiel HJ Intrarenal Reflux: Diagnosis at Contrast-Enhanced Voiding Urosonography. J Ultrasound Med. 2016;35(8):1811.

14. Fukui S, Watanabe M, Yoshino K. Intrarenal reflux in primary vesicoureteral reflux. Int J Urol. 2013 Jun;20(6):6316.

15. Kim SW, Im YJ, Hong CH, Han SW. The Clinical Significance of Intrarenal Reflux in Voiding Cystourethrography (VCUG). Korean J Urol. 2010;51(1):60-3. 